INRA Prod. Anim.,

2012, 25 (5), 407-418

\title{
La diversité de l'écosystème microbien du tractus digestif équin
}

\author{
S. SADET-BOURGETEAU', V. JULLIAND
}

${ }^{1}$ Unité de Recherche sur les Animaux d'Elevage, USC1335 Nutrition du cheval athlète, AgroSup Dijon,

F-21079 Dijon, France

Courriel : s.bourgeteau-sadet@agrosupdijon.fr

Chez le cheval adulte, le caecum et les différents segments du côlon hébergent un microbiote abondant qui assure des fonctions essentielles dont la digestion anaérobie des parois végétales, laquelle fournit des nutriments à l'animal hôte. Ce microbiote présente une grande diversité qu'il est important de bien caractériser pour comprendre comment les différents facteurs agissant sur le microbiote peuvent potentiellement affecter la santé du cheval adulte.

L'écosystème du gros intestin joue un rôle essentiel dans la nutrition et la santé des chevaux et des poneys adultes. En effet, le gros intestin est le site d'une activité microbienne intense. Il assure en particulier la dégradation et la fermentation des parois végétales en produits directement utilisables par l'hôte pour ses besoins d'entretien et de production. De plus, comme dans d'autres espèces animales, l'écosystème du gros intestin équin pourrait avoir un rôle de barrière à la colonisation par des pathogènes (Sekirov et al 2010). Il est donc important de prendre en compte l'intégrité du microbiote intestinal dans l'optimisation des performances sportives du cheval à l'exercice.

Le gros intestin équin se subdivise en une série de compartiments volumineux : le caecum, le côlon ventral droit, le côlon ventral gauche, le côlon dorsal gauche, le côlon dorsal droit et le côlon flottant (figure 1). Il se termine par l'ampoule rectale contenant les fèces.

L'écosystème du gros intestin équin présente des conditions environnementales favorables à l'activité microbienne : un $\mathrm{pH}$ proche de la neutralité, un environnement anaérobie, une température moyenne de $39^{\circ} \mathrm{C}$, un fort ralentissement du transit digestif, un brassage et un apport de substrat constants (tableau 1). Cet écosystème est peuplé par un microbiote abondant, caractérisé par une grande diversité d'espèces qui garantit l'équilibre des interactions au sein des communautés microbiennes et qui assure le bon fonctionnement de l'écosystème. Dans de nombreux travaux sur la diversité microbienne du tractus digestif, les mesures ont été réalisées sur des fèces et les résultats obtenus sur la communauté bactérienne fécale ont souvent été extrapolés à celle du gros intestin (Yamano et al 2008, Willing et al 2009). La validité scientifique de cette extrapolation est discutable aujourd'hui comme nous le verrons dans cette revue.

Historiquement, la diversité des écosystèmes microbiens a été étudiée par la mise en culture des espèces microbiennes ce qui a conduit à des sous-estimations de cette diversité. Dans la plupart des écosystèmes microbiens, la proportion de microorganismes cultivés est faible, en particulier du fait de la difficulté à reproduire les conditions environnementales caractéristiques du milieu originel (Zoetendal et al 2004). A notre connaissance, la proportion de bactéries cultivables au sein du tractus digestif équin n'est pas encore connue. Plus récemment les techniques de biologie moléculaire ont permis d'explorer la part de diversité microbienne méconnue dans les écosystèmes (Pedrós-Alió 2006). Chez le cheval quelques travaux ont été publiés sur le sujet. Nous valoriserons à la fois les travaux liés aux techniques de biologie moléculaire et les données obtenues par les techniques culturales afin d'avoir une vision la plus complète possible de la diversité microbienne présente dans le gros intestin équin.

Comme mis en évidence dans d'autres écosystèmes (Loreau et Behera 1999), la perte de diversité microbienne au niveau intestinal pourrait être source de déséquilibres entre les espèces microbiennes présentes, entraînant l'apparition de dysfonctionnements voire de maladies

Figure 1. Les différents segments du gros intestin équin.

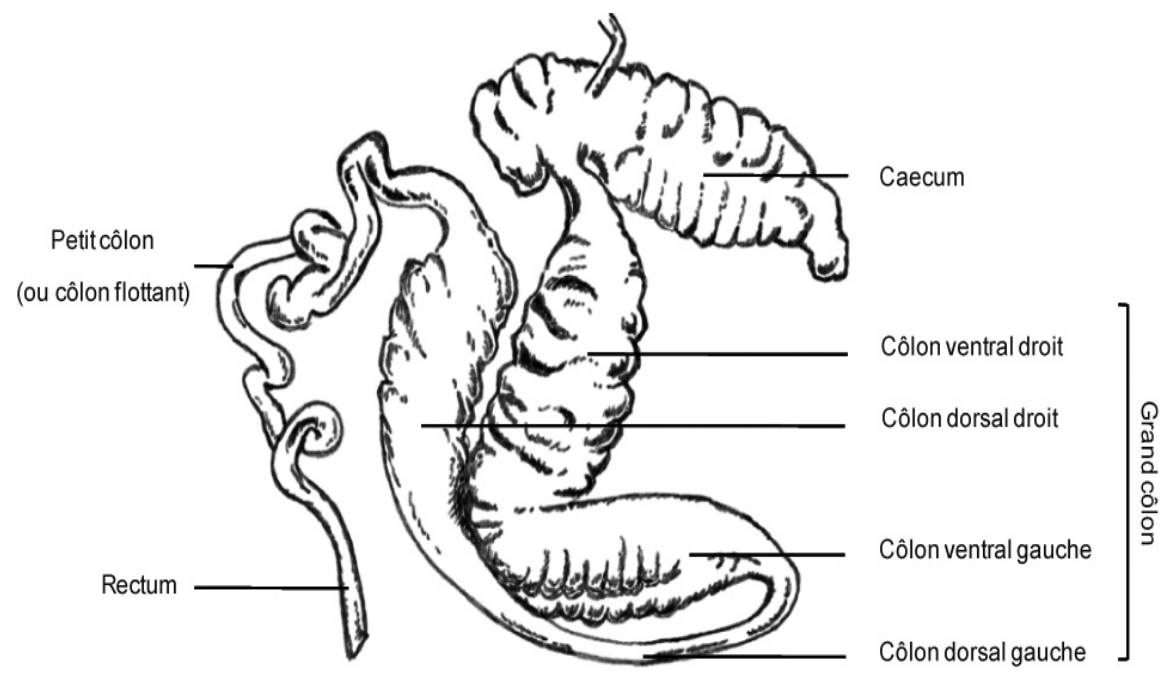


Tableau 1. Comparaison des conditions environnementales présentes dans le caecum et le côlon des équins.

\begin{tabular}{|l|c|c|l|}
\hline & Caecum & Côlon & \multicolumn{1}{c|}{ Références } \\
\hline $\mathrm{pH}$ & 6,3 à 7,8 & 6,3 à 7,5 & $\begin{array}{l}\text { Tisserand et Masson (1976), } \\
\text { Wolter et al (1978) }\end{array}$ \\
\hline Volume (L) & 30 & 80 à 90 & Nickel et al (1979) \\
\hline Température & \multicolumn{2}{|c|}{38 à $40^{\circ} \mathrm{C}$} & $\begin{array}{l}\text { Philippeau (communication } \\
\text { personnelle) }\end{array}$ \\
\hline Teneur en eau & 88 à $97 \%$ & 76 à $85 \%$ & $\begin{array}{l}\text { Hintz et al (1971), Wolter et al } \\
\text { (1978), Goodson et al (1988) }\end{array}$ \\
\hline Potentiel redox & - & -488 à $-212 \mathrm{mV}$ & $\begin{array}{l}\text { Da Veiga et al (2005), } \\
\text { Philippeau et al (2009) }\end{array}$ \\
\hline
\end{tabular}

telles que les coliques et les fourbures ${ }^{1}$. Plusieurs facteurs sont potentiellement perturbateurs de la diversité microbienne et donc du fonctionnement de l'écosystème : des facteurs liés à l'hôte et/ou des facteurs environnementaux dont le plus documenté est l'alimentation.

Cette revue se focalise sur le microbiote intestinal de l'équin adulte. Elle décrit sa complexité dans les différents compartiments du gros intestin et dans les fèces ainsi que les facteurs pouvant modifier sa diversité. L'impact d'une modification du microbiote digestif équin sur la santé de l'hôte a été encore peu étudié. Néanmoins, nous ferons état des quelques études ayant établi un lien entre les modifications du microbiote intestinal et les pathologies digestives.

\section{$1 /$ Diversité des micro- organismes présents dans le tractus digestif équin}

Le microbiote intestinal équin compte des protozoaires, des bactéries, des champignons, des Archaea (ou archées) et des virus. Du fait de leur grande taille, les protozoaires ont été mis en évidence dès
1843 dans le tractus digestif équin (Gruby et Delafond 1843). Les premières études réalisées sur la flore bactérienne du caecum de cheval (Choukevitch 1911) ne dénombraient pas les espèces anaérobies strictes. Par la suite, dans le contenu caecal de poney, il a été montré que $38 \%$ (McCreery et al 1971, Kern et al 1973) à $80 \%$ (Kern et al 1974) des bactéries présentes étaient extrêmement sensibles à l'oxygène. Ces pourcentages sont vraisemblablement sous-estimés. La technique de culture en anaérobiose stricte proposée par Hungate (1950) a constitué une étape déterminante et a permis de cultiver et dénombrer les bactéries anaérobies strictes. En 1961, la présence de champignons (Geaotrichum candidum) a été détectée dans le contenu du gros intestin équin (Batista et al 1961). C'est en 1970 que des virus, et plus précisément des bactériophages, ont été observés dans les contenus caecal et colique des équins (Alexander $e t$ al 1970). Enfin, en 1996, les Archaea ont été mises en évidence pour la première fois dans les fèces équines (Morvan et al 1996).

\section{1 / Diversité des protozoaires}

Dans le caecum et le côlon, la concentration en protozoaires est estimée à $10^{4}$ $10^{5}$ microorganismes par $\mathrm{mL}$ de contenu digestif (Adam 1950, 1953, Ozeki et al

Tableau 2. Concentrations microbiennes dans le caecum, le côlon et les fèces des équins.

\begin{tabular}{|c|c|c|c|c|c|c|c|}
\hline $\begin{array}{l}\text { Segment } \\
\text { digestif }\end{array}$ & $\begin{array}{c}\text { Bacteriophages } \\
\text { (particules/g) }\end{array}$ & $\begin{array}{c}\text { Fungi } \\
\text { (zoospores } / \mathrm{mL} \text { ) }\end{array}$ & $\begin{array}{l}\text { Protozoaires } \\
\text { (cellules } / \mathrm{mL} \text { ) }\end{array}$ & $\begin{array}{c}\text { Archaea } \\
\text { (cellules } / \mathrm{mL} \text { ) }\end{array}$ & $\begin{array}{l}\text { Bactéries } \\
\text { totales }\end{array}$ & $\begin{array}{l}\text { Bactéries } \\
\text { anaérobies } \\
\text { totales }\end{array}$ & Références \\
\hline Caecum & NR & $10^{2}-10^{4}$ & $10^{4}-10^{5}$ & $10^{5}$ & $\begin{array}{l}10^{7}-10^{9} \\
U F C / m L\end{array}$ & $\begin{array}{c}10^{7}-10^{9} \\
\text { UFC } / \mathrm{mL}\end{array}$ & $\begin{array}{l}\text { Adam (1950, 1953), Kern et al (1973), Ozeki et al (1973), Kern et al } \\
\text { (1974), Orpin (1981), Mackie et Wilkins (1988), Moore et Dehority (1993), } \\
\text { Gaillard-Martinie et al (1995), Morvan et al (1996), Julliand et al (1999, } \\
\text { 2001), Medina et al (2002), de Fombelle et al (2003), Jansen et al (2007), } \\
\text { Respondek et al (2007), Jouany et al (2009) }\end{array}$ \\
\hline Côlon & NR & $10^{3}$ & $10^{4}-10^{5}$ & NR & $\begin{array}{l}10^{7}-10^{9} \\
U F C / m L\end{array}$ & $\begin{array}{l}10^{7}-10^{9} \\
\text { UFC } / \mathrm{mL}\end{array}$ & $\begin{array}{l}\text { Adam (1950, 1953), Ozeki et al (1973), Kern et al (1974), Mackie et } \\
\text { Wilkins (1988), Moore et Dehority (1993), Julliand et al (2001), Medina et } \\
\text { al (2002), de Fombelle et al (2003), Respondek et al (2007), Muhonen et } \\
\text { al (2008, 2009), Müller et al (2008), Jouany et al (2009) }\end{array}$ \\
\hline Fèces & $10^{3}-10^{11}$ & $10^{1}-10^{2}$ & $10^{4}-10^{6}$ & NR & $\begin{array}{l}10^{9}-10^{11} \\
\text { UFC / }\end{array}$ & $\begin{array}{l}10^{8}-10^{10} \\
U F C / g\end{array}$ & $\begin{array}{l}\text { Adam (1950), Peltonen et al (1978), Ike et al (1983,1985), Imai et al } \\
\text { (1999), Koike et al (2000), Garrett et al (2002), Yuyama et al (2004), } \\
\text { Kobayashi et al (2006), Golomidova et al (2007), Kulikov et al (2007), } \\
\text { Müller et al (2008), Gürelli et Göçmen (2009, 2011, 2012), Letarov et } \\
\text { Kulikov (2009), Göçmen et al (2012) }\end{array}$ \\
\hline
\end{tabular}

NR : Non Référencé ; UFC : Unité Formant Colonie.

\footnotetext{
${ }^{1}$ Inflammation des tissus du pied, notamment des antérieurs, due en particulier à une alimentation trop riche en énergie. Elle peut devenir chronique et entraîner de lourdes conséquences cliniques (basculement de la troisième phalange).
} 
Tableau 3. Genres de protozoaires mis en évidence dans le tractus digestif équin (caecum, côlon et fèces) (d'après Adam 1950, 1953, Ozeki et al 1973, Ike et al 1983,1985, Imai et al 1999, Gürelli et Göçmen 2009, 2011, 2012, Göçmen et al 2012).

\begin{tabular}{|c|c|c|c|c|}
\hline Genre & Caecum & Côlon & $\begin{array}{c}\text { Côlon dorsal / } \\
\text { Petit côlon / Rectum }\end{array}$ & Fèces \\
\hline Allantosoma & $x$ & $\mathrm{x}$ & $x$ & $\mathrm{x}$ \\
\hline Alloizona & $x$ & $x$ & $x$ & $x$ \\
\hline Ampullacula & & $x$ & & $x$ \\
\hline Blepharoconus & $\mathrm{x}$ & $\mathrm{x}$ & $x$ & $\mathrm{x}$ \\
\hline Blepharocorys & $x$ & $x$ & $x$ & $x$ \\
\hline Blepharoprosthium & $\mathrm{x}$ & $\mathrm{x}$ & $x$ & $x$ \\
\hline Blepharosphaera & & $x$ & $x$ & $x$ \\
\hline Blepharozoum & $x$ & $\mathrm{x}$ & & $\mathrm{x}$ \\
\hline Bundleia & $x$ & $x$ & $\mathrm{x}$ & $x$ \\
\hline Buetschlia & $x$ & $x$ & & \\
\hline Charonnautes & & & $\mathrm{x}$ & $\mathrm{x}$ \\
\hline Chlamydobundleia & & & & $x$ \\
\hline Circodinium & & & & $\mathrm{x}$ \\
\hline Cochliatoxum & & & $\mathrm{x}$ & $x$ \\
\hline Cycloposthium & $x$ & $\mathrm{x}$ & $x$ & $\mathrm{x}$ \\
\hline Didesmis & $\mathrm{x}$ & $\mathrm{x}$ & $x$ & $\mathrm{x}$ \\
\hline Ditoxum & & $x$ & $x$ & $x$ \\
\hline Hemiprorodon & & & $\mathrm{x}$ & $\mathrm{x}$ \\
\hline Holophryoides & $\mathrm{x}$ & $\mathrm{x}$ & $x$ & $x$ \\
\hline Gassovskiella & & & & $\mathrm{x}$ \\
\hline Ochoterenaia & & & & $x$ \\
\hline Paraisotricha & $\mathrm{x}$ & $\mathrm{x}$ & $x$ & $x$ \\
\hline Paraisotrichopsis & & & & $x$ \\
\hline Polymorpha & $\mathrm{x}$ & $\mathrm{x}$ & $x$ & $x$ \\
\hline Polymorphella & & & & $\mathrm{x}$ \\
\hline Prorodonopsis & & & & $x$ \\
\hline Spirodinium & & $x$ & $x$ & $x$ \\
\hline Tetratoxum & & $x$ & $x$ & $x$ \\
\hline Triadinium & & $x$ & $x$ & $x$ \\
\hline Tripalmaria & & $\mathrm{x}$ & $x$ & $\mathrm{x}$ \\
\hline Walskana & & & & $x$ \\
\hline
\end{tabular}

1973, Moore et Dehority 1993). Cette concentration est variable en fonction du segment digestif considéré et serait deux (Ozeki et al 1973, Moore et Dehority 1993) à cent (Adam 1950, 1953) fois plus importante dans le côlon que dans le caecum. Dans les fèces, la concentration en protozoaires serait de $10^{4}$ $10^{6}$ microorganismes par $\mathrm{mL}$ de contenu digestif (tableau 2). Récemment, Dougal et al (2012) ont évalué la quantité de protozoaires présents dans le caecum, le côlon dorsal droit et les fèces en quantifiant par PCR une portion du gène $\mathrm{ADNr} 18 \mathrm{~S}$. Ces auteurs ont observé que la concentration en gène $\mathrm{ADNr} 18 \mathrm{~S}$ était significativement plus élevée dans le côlon dorsal droit que dans le caecum. Ils ont également montré que la concentration en gène $\mathrm{ADNr} 18 \mathrm{~S}$ était significativement plus élevée dans le côlon rente et plus importante que celle observée dans le caecum et le côlon (tableau 3 ).

Peu d'études ont été menées sur le rôle des protozoaires dans la digestion intestinale équine. Moore et Dehority (1993) suggèrent que ces microorganismes n'auraient pas un rôle essentiel dans la fermentation des aliments ingérés par l'animal alors que BonhommeFlorentin (1985) conclut qu'ils participeraient à la dégradation physique des tissus végétaux. Cet auteur montre dans le caecum équin que les ciliés sont attachés aux fragments végétaux et qu'ils ingèrent des chloroplastes. L'ingestion de matériel cellulosique conduit à l'hypothèse d'une dégradation possible de la cellulose par les protozoaires (Bonhomme-Florentin 1985). Des études complémentaires, comme la réalisation d'une élimination des protozoaires par défaunation, sont cependant nécessaires pour mieux identifier, chez le cheval, l'importance de ces microorganismes dans les processus de digestion.

\section{2 / Diversité bactérienne}

a) Diversité bactérienne dans le gros intestin

Dans le caecum et le côlon, la concentration en bactéries totales (c'est-à-dire aérobies et anaérobies) a été évaluée entre $10^{7}$ et $10^{9}$ Unité Formant Colonie (UFC) / $\mathrm{mL}$ de contenu digestif (tableau 2) et celle en bactéries anaérobies totales est comprise dans cette même fourchette de valeurs (tableau 2).

La communauté bactérienne du caecum et du côlon a été décrite via l'utilisation d'outils de biologie moléculaire : avec des banques de clones (Daly et al 2001) ou des sondes oligonucléotidiques (Daly et Shirazi-Beechey 2003, Daly et al 2012). Seulement 5\% des séquences bactériennes identifiées dans le côlon ventral droit, le côlon dorsal gauche et le côlon transverse correspondent à des microorganismes connus (Daly et al 2001). Ceci suggère l'existence d'une flore intestinale spécifique de l'espèce équine et souligne le manque d'information disponible actuellement sur cette communauté chez les équins. Dans le gros intestin équin, il a été montré que les phyla des Firmicutes (56 à 72\%) et des Bacteroidetes (14 à 28\%) étaient majoritaires (Daly et al 2001, 2012, Daly et Shirazi-Beechey 2003). De par leur importance, les Firmicutes seraient, au sein du tractus digestif équin, comme chez d'autres espèces animales, un groupe phylogénétique essentiel. En effet, ce phylum comprend une majorité de bactéries cellulolytiques et fibrolytiques telles que Clostridium spp., Ruminococcus spp., Butyrivibrio spp., et Eubacteria spp (Daly et al 2001). La prédominance 
Tableau 4. Concentrations des principaux groupes fonctionnels bactériens présents dans le caecum, le côlon et les fèces des équins.

\begin{tabular}{|c|c|c|c|c|c|c|c|c|c|}
\hline $\begin{array}{c}\text { Segment } \\
\text { digestif }\end{array}$ & $\begin{array}{l}\text { Lactobacilles } \\
\text { (UFC / g) }\end{array}$ & $\begin{array}{c}\text { Bactéries } \\
\text { productrices } \\
\text { de lactate } \\
\text { (UFC / g) }\end{array}$ & \begin{tabular}{|c|} 
Bactéries \\
utilisatrices \\
de lactate \\
(UFC / g)
\end{tabular} & $\begin{array}{l}\text { Streptocoques } \\
\text { (UFC / g) }\end{array}$ & $\begin{array}{c}\text { Bactéries } \\
\text { cellulolytiques } \\
\text { (UFC / g) }\end{array}$ & $\begin{array}{c}\text { Bactéries } \\
\text { amylolytiques } \\
\text { (UFC / g) }\end{array}$ & $\begin{array}{c}\text { Bactéries } \\
\text { glycolytiques } \\
\text { (UFC / g) }\end{array}$ & $\begin{array}{c}\text { Bactéries } \\
\text { proteolytiques } \\
\text { (UFC / g) }\end{array}$ & Références \\
\hline Caecum & $10^{5}-10^{7}$ & NR & $10^{5}-10^{8}$ & $10^{5}-10^{7}$ & $10^{4}-10^{7}$ & $10^{8}$ & $10^{8}$ & $10^{8}$ & $\begin{array}{l}\text { Kern et al (1973), Mackie et Wilkins } \\
\text { (1988), Moore et Dehority (1993), } \\
\text { Julliand et al (1999, 2001), Medina et al } \\
\text { (2002), de Fombelle et al (2003), } \\
\text { Jansen et al (2007), Respondek et al } \\
\text { 2007, 2008), Jouany et al (2009) }\end{array}$ \\
\hline Côlon & $10^{5}-10^{8}$ & $10^{5}-10^{6}$ & $10^{5}-10^{8}$ & $10^{4}-10^{7}$ & $10^{4}-10^{8}$ & $10^{8}$ & $10^{8}$ & $10^{6}-10^{8}$ & $\begin{array}{l}\text { Mackie et Wilkins (1988), Moore et } \\
\text { Dehority (1993), Julliand et al (2001), } \\
\text { Medina et al (2002), de Fombelle et al } \\
\text { (2003), Respondek et al (2007, 2008), } \\
\text { Muhonen et al (2008), Müller et al } \\
\text { (2008), Jouany et al (2009), Muhonen } \\
\text { et al (2009) }\end{array}$ \\
\hline
\end{tabular}

NR : Non Référencé ; UFC : Unités Formant Colonies.

des Firmicutes et des Bacteroidetes au sein des écosystèmes intestinaux équins est en accord avec ce qui a été observé dans le rumen (Whitford et al 1998, Tajima et al 2000, Edwards et al 2004, Yu et al 2006). Chez le cheval, dans le caecum et le côlon (côlon ventral droit, côlon dorsal gauche et côlon transverse), d'autres phyla ont été mis en évidence tels que les Spirochetaceae (3\%), les Verrucomicrobiales $(3 \%)$, les «High \% G+C Gram-positive Bacteria» (HGCGPB ; $<1 \%$ ) et les Proteobacteria $(<1 \%$ ) (Daly et al 2001). Plus spécifiquement, dans le côlon, la proportion de Spirochaetaceae a été évaluée entre 10 et $11 \%$ du microbiote total (Daly et al 2012).

La concentration en bactéries cellulolytiques varie entre $10^{4}$ et $10^{8} \mathrm{UFC} / \mathrm{g}$ de contenu ${ }^{2}$ dans le gros intestin (caecum et côlon) (tableau 4). Aucune différence de concentration en bactéries cellulolytiques n'a été mise en évidence entre le caecum et le côlon ventral droit ou le côlon dorsal gauche (de Fombelle et al 2003). En revanche, il semblerait que la concentration en bactéries cellulolytiques soit plus importante dans le caecum que dans l'ampoule rectale (fèces) (Kern et al 1974). Dans le tractus digestif équin, le caecum serait le principal site de colonisation des parois végétales par les bactéries. Plusieurs espèces bactériennes cellulolytiques ont été isolées dans les différents compartiments du gros intestin. Il s'agit de Ruminococcus flavefaciens, Ruminococcus albus, Fibrobacter succinogenes, Clostridium spp., Butyrivibrio spp., et Eubacterium spp. (Lin et Stahl 1995, Julliand et al 1999, Daly et al 2001) (tableau 5). Les souches de $R$.
Tableau 5. Genres et espèces de bactéries mis en évidence dans le tractus digestif équin (caecum, côlon et fèces) (d'après Baruc et al 1983, Maczulak et al 1985, Lin et Stahl 1995, Julliand et al 1999, Daly et al 2001, 2012, Morotomi et al 2002, Al Jassim et al 2005, Julliand 2005, Endo et al 2007, 2008, 2009, Morita et al 2007, 2009, Willing et al 2009).

\begin{tabular}{|c|c|c|c|}
\hline Genre - Espèce & Caecum & Côlon & Fèces \\
\hline Bifidobacterium boum & & & $\mathrm{x}$ \\
\hline Bifidobacterium urinalis & & & $x$ \\
\hline Butyrivibrio spp. & $\mathrm{x}$ & $\mathrm{x}$ & \\
\hline Clostridium spp. & $x$ & $x$ & \\
\hline Eubacterium spp. & $\mathrm{x}$ & $\mathrm{x}$ & \\
\hline Fibrobacter succinogenes & $x$ & $x$ & \\
\hline Lactobacillus agilis & & & $x$ \\
\hline Lactobacillus buchneri & & & $\mathrm{x}$ \\
\hline Lactobacillus delbrueckii & & & $x$ \\
\hline Lactobacillus equi & & & $x$ \\
\hline Lactobacillus equigenerosi & & & $x$ \\
\hline Lactobacillus gastricus & & & $\mathrm{x}$ \\
\hline Lactobacillus hayakitensis & & & $\mathrm{x}$ \\
\hline Lactobacillus johnsonii & & & $x$ \\
\hline Lactobacillus mucosae & $x$ & $x$ & \\
\hline Lactobacillus reuteri & & & $x$ \\
\hline Lactobacillus salivarius & $x$ & $x$ & $x$ \\
\hline Lactobacillus vitulinus & & & $\mathrm{x}$ \\
\hline Megasphera sp. & $x$ & $x$ & \\
\hline Mitsuokella jalaludinii & $x$ & $x$ & \\
\hline Parascardovia denticolens & & & $x$ \\
\hline Ruminococcus albus & $x$ & $x$ & \\
\hline Ruminococcus flavefaciens & $x$ & $x$ & \\
\hline Streptococcus bovis & $x$ & $x$ & $x$ \\
\hline Streptococcus equinus & $x$ & $x$ & $x$ \\
\hline Veillonella sp. & $\mathrm{x}$ & $\mathrm{x}$ & \\
\hline
\end{tabular}

2 On peut considérer que les concentrations exprimées par g ou par $\mathrm{mL}$ de contenu selon les publications sont équivalentes, un g de contenu occupant environ $1 \mathrm{~mL}$. 
flavefaciens présentes dans le caecum sont spécifiques des équidés (Julliand et al 1999). Plusieurs travaux concluent que $R$. flavefaciens serait l'espèce cellulolytique majoritaire dans le caecum (9\% des ARNr totaux extraits) (Julliand et al 1999) et plus généralement dans le gros intestin (Hastie et al 2008). Lin et Stahl (1995) rapportent que F. succinogenes représenterait $12 \%$ des $\mathrm{ARNr}$ totaux extraits du contenu caecal d'un animal, alors que Daly et al (2001) n'ont identifié, dans le gros intestin, aucune Unité Taxonomique Opérationnelle (UTO) comme étant proche de F. succinogenes. Dans le côlon équin, la famille des Lachnospiraceae comprenant les espèces bactériennes Ruminococcus spp, Clostridium spp., Butyrivibrio spp., et Eubacterium spp., représenterait 9,6 à $27,6 \%$ du microbiote total (Daly et al 2012); les Fibrobacter et les Ruminococcaceae seraient en proportion moindre avec de valeurs comprises respectivement entre 0,4 et $2,7 \%$ et entre 0,2 et $1,4 \%$ du microbiote total (Daly et al 2012). Plus précisément, dans le côlon, $F$. succinogenes représenterait $4 \%$ des ARNr totaux extraits soit trois fois moins que ce qui a pu être quantifié dans le caecum (Lin et Stahl 1995). Toutefois cette variation de la proportion de $F$. succinogenes entre le caecum et le côlon (Lin et Stahl 1995) n'a pas été observée par Hastie et al (2008).

Chez les équidés, la colonisation des tissus végétaux par les bactéries cellulolytiques n'a pas été étudiée. Les souches caecales de $R$. flavefaciens présentes dans le caecum sont aptes à dégrader la cellulose et à fermenter les glucides mais les mécanismes de digestion ne sont pas connus précisément (Julliand et al 1999).

Le gros intestin des équins abrite des bactéries amylolytiques, glycolytiques, utilisatrices de lactate et protéolytiques. La concentration en bactéries amylolytiques a été évaluée à $10^{8} \mathrm{UFC} / \mathrm{g}$ de contenu caecal ou colique (tableau 4). Des concentrations identiques ont été observées pour les bactéries glycolytiques $\left(10^{8} \mathrm{UFC} / \mathrm{g}\right.$ de contenu caecal ou colique) (tableau 4). Les bactéries amylolytiques et glycolytiques comprennent essentiellement des streptocoques et des lactobacilles (Vörös 2008), bactéries productrices entre autres de lactate. La concentration en streptocoques et lactobacilles caecaux est, pour chaque groupe bactérien considéré, de $10^{5}-10^{7} \mathrm{UFC} / \mathrm{g}$ de contenu (tableau 4). Dans le côlon, les concentrations bactériennes observées sont de $10^{4}-10^{7} \mathrm{UFC} / \mathrm{g}$ de contenu pour les streptocoques et de $10^{5}-10^{8}$ UFC/g de contenu pour les lactobacilles (tableau 4). Les bactéries appartenant au groupe Bacillus-Lactobacillus-Streptococcus représenteraient 3,9 à $9,2 \%$ du microbiote total (Daly et al 2012).
Streptococcus bovis, S. equinus (Julliand 2005), Lactobacillus salivarus, L. mисоsae et Mitsuokella jalaludinii (Al Jassim et al 2005) ont été décrites comme étant les principales bactéries productrices de lactate dans le caecum et le côlon équin (tableau 5). Streptococcus bovis est apparu comme étant minoritaire dans le caecum et le côlon (moins de $2 \%$ de la totalité des clones) (Daly et al 2001). Alors que les bifidobactéries sont connues pour être des bactéries productrices de lactate dans le tractus digestif, chez le cheval, aucune étude n'a encore mis en évidence la présence de ces microorganismes dans le caecum et le côlon équin (Endo et al 2007, 2009).

Dans le caecum et le côlon, les concentrations en bactéries utilisatrices de lactate seraient comprises, pour les deux compartiments, entre $10^{5}$ et $10^{8} \mathrm{UFC} / \mathrm{g}$ de contenu (tableau 4). En utilisant des techniques culturales classiques, les genres bactériens Veillonella sp. et Megasphera sp. ont été identifiés comme étant les principaux utilisateurs de lactate dans le gros intestin équin (tableau 5). Les Veillonellaceae représenteraient dans le côlon environ 1,2\% du microbiote total (Daly et al 2012).

Les bactéries amylolytiques, glycolytiques et utilisatrices de lactate présentes dans le gros intestin équin (caecum et côlon) sont aptes à dégrader les glucides non pariétaux d'origine alimentaire tels que l'amidon et les glucides facilement fermentescibles. Les mécanismes de digestion ne sont pas connus précisément.

La concentration en bactéries protéolytiques caecales serait de $10^{8} \mathrm{UFC} / \mathrm{g}$ de contenu ; dans le côlon cette concentration varierait entre $10^{6}$ et $10^{8} \mathrm{UFC} / \mathrm{g}$ de contenu (tableau 4). Dans le caecum, l'espèce bactérienne protéolytique majoritaire serait Streptococcus bovis (Kern et al 1973).

Les souches bactériennes caecales sont aptes à dégrader les acides aminés, les protéines et l'ammoniac mais peu sont capables de dégrader l'urée (Baruc et al 1983). L'activité protéolytique de la microflore bactérienne caecale et colique et son implication dans l'utilisation de l'azote protéique et non protéique ainsi que dans la fourniture en acides aminés sont encore peu connues.

\section{b) Diversité bactérienne dans les fèces}

La concentration en bactéries totales (c'est-à-dire aérobies et anaérobies) varie de $10^{9}$ à $10^{11} \mathrm{UFC} / \mathrm{g}$ de contenu fécal (tableau 2). La concentration en bactéries anaérobies totales est comprise entre $10^{8}$ et $10^{10} \mathrm{UFC} / \mathrm{g}$ de contenu fécal (tableau 2) (Garrett et al 2002, Müller et al 2008). Différents phyla bactériens ont été mis en évidence dans les fèces équines: Firmicutes, Bacteroidetes, Verrucomicrobia, Proteobacteria, Spirochaetes (Yamano et al 2008, Shepherd et al 2011, 2012, Costa et al 2012), TM7, Actinobacteria, Fibrobacteres, Tenericutes, Cyanobacteria (Shepherd et al 2012). Dans toutes les études recensées, le phylum des Firmicutes était majoritairement présent dans les fèces équines avec des pourcentages variant entre 38,5 et $68 \%$ des bactéries totales (Yamano et al 2008, Shepherd et al 2011, 2012, Costa et al 2012). Selon les travaux considérés, le phylum des Bacteroidetes représenterait 1,9 à $47,4 \%$ des bactéries totales présentes dans les fèces des chevaux. (Yamano et al 2008, Shepherd et al 2011, Costa et al 2012, Shepherd et al 2012). Les autres phyla mis en évidence étaient en proportion moindre avec: Verrucomicrobia $(4,0$ à $8,8 \%$ des bactéries totales) (Yamano et al 2008, Shepherd et al 2011, 2012), Proteobacteria (1,8 à $10,2 \%$ ) (Shepherd et al 2011, 2012, Costa et al 2012), Spirochaetes (2 à $3,5 \%$ ) (Yamano et al 2008, Shepherd et al 2012), TM7 (1,8\%), Actinobacteria (1.6\%), Fibrobacteres (0,75\%), Tenericutes $(0,13 \%)$, Cyanobacteria $(0,12 \%)$ (Shepherd et al 2012).

La proportion de Firmicutes dans les fèces équines est moins importante que dans le caecum et le côlon (Daly et al 2001, Daly et Shirazi-Beechey 2003, Yamano et al 2008, Shepherd et al 2011, 2012). En revanche, excepté pour les travaux de Shepherd (2011, 2012), la proportion de Bacteroidetes est plus importante dans les fèces que dans le caecum et le côlon (Daly et al 2001, Daly et Shirazi-Beechey 2003, Yamano et al 2008, Shepherd et al 2011, 2012). La communauté bactérienne fécale semble donc différente de celle du côlon ou encore du caecum.

La concentration en bactéries cellulolytiques présente dans les fèces varie entre $10^{4}$ et $10^{5} \mathrm{UFC} / \mathrm{g}$ de contenu (tableau 4) (de Fombelle et al 2003, Müller et al 2008), et serait similaire à celle mesurée dans le caecum ou le côlon (de Fombelle et al 2003, Müller et al 2008).

Dans les fèces équines, des bactéries productrices de lactate ont été mises en évidence. La concentration en streptocoques varie entre $10^{5}$ et $10^{8} \mathrm{UFC} / \mathrm{g}$ de fèces (tableau 4). Les espèces prédominantes sont Streptococcus bovis et $S$. equinus. La concentration en lactobacilles varie entre $10^{5}$ et $10^{\circ} \mathrm{UFC} / \mathrm{g}$ de fèces (tableau 4). Différentes espèces de lactobacilles ont été mises en évidence dans les fèces équines et ces dernières 
sont répertoriées dans le tableau 5 . Parmi ces espèces, Lactobacillus hayakitensis, L. equigenerosi et $L$. equi seraient majoritaires (Morita et al 2009). Contrairement aux autres espèces de lactobacilles, Lactobacillus equigenerosi et $L$. equi seraient spécifiques des fèces équines (Morotomi et al 2002, Endo et al 2008). D'autres bactéries productrices de lactate comme Mitsuokella jalaludinii (Al Jassim et al 2005) ont aussi été mises en évidence dans les fèces de chevaux. Contrairement à ce qui a été observé dans le gros intestin, le genre Bifidobacterium serait présent dans les fèces de cheval. Une étude rapporte que ce genre serait présent à $10^{3-}-10^{5} \mathrm{UFC} / \mathrm{g}$ de fèces (Endo et al 2007). Parascardovia denticolens serait l'espèce prédominante au sein du groupe des bifidobactéries fécales équines mais d'autres espèces comme Bifidobacterium boum et $B$. urinalis ont également été identifiées (tableau 5).

A notre connaissance, aucune étude n'a fait référence à la concentration en bactéries protéolytiques dans les fèces chez les équins.

\section{3 / Diversité fongique}

Dans le caecum équin, la concentration fongique varierait entre $10^{2}$ et $10^{4}$ zoospores/mL de contenu (tableau 2). Une étude réalisée sur des poneys a montré que la concentration en champignons présents dans le contenu colique $\left(38 \times 10^{2} / \mathrm{g}\right)$ était dix fois supérieure à celle observée dans le contenu caecal $\left(3,5 \times 10^{2} / \mathrm{g}\right)$ (Moore et Dehority 1993). Comme cela a été observé dans le rumen, l'évaluation de la population fongique in vivo est difficile. En effet, le nombre de zoospores présentes dans le rumen ne peut être relié ni à un nombre de sporocystes, ni à une quantité de rhizoïdes. Le dosage de la chitine, constituant spécifique des parois fongiques, est fiable pour des cultures pures, mais pas in vivo. L'étude de la communauté fongique est également limitée par les difficultés de mise en culture. Ainsi, l'utilisation d'outils moléculaires constitue une alternative permettant d'évaluer la densité fongique sans passer par la culture de ces microorganismes.

La concentration en champignons anaérobies évaluée par PCR quantitative (via l'amplification du gène $\mathrm{ADNr} 5,8 \mathrm{~S}$ ), relativement à la concentration de bactéries totales, est similaire dans le caecum, le côlon et les fèces équins (Dougal et al 2012).

Des observations microscopiques de contenus digestifs et l'utilisation de techniques de cultures ont permis de décrire la population fongique présente dans le caecum équin (Vavra et Joyon 1966,
Orpin 1981, Gold et al 1988, Li et al 1989, Gaillard-Martinie et al 1992 , 1995, Li et Heath 1993, Julliand et al 1998). Il a ainsi été établi que ces champignons microscopiques étaient strictement anaérobies, appartenaient à la classe des phycomycètes (Orpin 1981) et en majorité au genre Piromyces. Plus précisément, trois espèces ont été mises en évidence chez les équins : $P$. mae (Li et al 1989, Gaillard-Martinie et al 1992), $P$. equi (Li et Heath 1993) et $P$. Citronii (Gaillard-Martinie et al 1995). In vitro, $P$. Citronii aurait un taux de croissance supérieur à celui des souches du rumen (Julliand et al 1998); ceci pourrait être le reflet d'une adaptation physiologique de la souche à l'écosystème caecal. Caecomyces equi (Gold et al 1988) et Neocallimastix equi (Vavra et Joyon 1966) seraient également des genres constitutifs de la faune fongique intestinale équine. Par pyro-séquençage, la diversité de la communauté fongique a pu être mieux appréhendée dans les fèces (Liggenstoffer et al 2010). Ainsi, quatre nouvelles lignées fongiques ont pu être identifiées (NG1,NG2, NG3 et NG5). Parmi ces lignées, $N G 1$ et $N G 3$ représenteraient la majorité des séquences fongiques identifiées (en moyenne 42 et $51,3 \%$ respectivement). Les genres $\mathrm{NeO}$ callimastix, Piromyces, Caecomyces et Anaeromyces ont également été mis en évidence dans les fèces équines, mais en proportions largement minoritaires par rapport aux lignées $N G 1$ et $N G 3$ (en moyenne $1,9,0,3,7,9$ et $0,3 \%$ des séquences identifiées respectivement). Les lignées $N G 2$ et $N G 5$ étaient également minoritaires dans les fèces avec 1,3 et $0,06 \%$ des séquences identifiées (Liggenstoffer et al 2010).

Chez le cheval, les champignons anaérobies caecaux ont une très grande capacité à dégrader la cellulose (Teunissen et Op den Camp 1993, Julliand et al 1998) mais les mécanismes de la digestion sont encore mal connus.

\section{4 / Diversité des Archaea}

Chez les chevaux, la concentration en Archaea, et plus précisément en Archaea methanogènes, a été évaluée dans le caecum à $6,3 \times 10^{5}$ cellules $/ \mathrm{mL}$ (tableau 2 ). Récemment, Dougal et al (2012), par quantification PCR du gène $m c r A$, ont observé que le côlon dorsal droit contenait une concentration en gène $\mathrm{mcr} A$ significativement plus élevée que ce qui pouvait être mesuré dans le caecum ou les fèces (Dougal et al 2012).

Dans les fèces équines, le genre Methanobrevibacter serait prédominant (Miller et Wolin 1986, Miller et al 1986, Lin et Miller 1998). En se basant sur les différents travaux effectués au niveau du rumen, les Archaea métha- nogènes joueraient un rôle dans la production de méthane dans le gros intestin équin.

\section{5 / Diversité virale}

Chez le cheval, la quantité de particules phagiques présentes dans les fèces varierait entre $10^{3}$ et $10^{11}$ phages $/ \mathrm{g}$ de fèces (tableau 2). Via l'utilisation de banque de clones, une étude a montré que cette communauté virale représentait $63 \%$ de la communauté microbienne fécale totale (Cann et al 2004). Cinquantedeux pourcents de ces virus appartenaient au genre des Siphoviridae, 26\% n'ont pu être classés dans la nomenclature connue, $17 \%$ appartenaient au genre Myoviridae et $4 \%$ à celui des Podoviridae (Cann et al 2004). Le pourcentage de clones restant était constitué par des Othopoxvirus (Cann et al 2004). Dans une autre étude, basée sur l'observation microscopique classique, la présence de plus de 69 types de phages de morphologie différente a été mis en évidence dans des échantillons de fèces provenant d'un seul cheval (Kulikov et al 2007). Actuellement, chez le cheval, la diversité de la communauté virale caecale et colique n'a pas encore été évaluée via l'utilisation d'outils de biologie moléculaire.

A notre connaissance, le rôle des bactériophages présents dans le gros intestin équin n'a pas encore été étudié. Comme chez les ruminants, ces virus seraient sans doute capables de lyser les bactéries assurant ainsi un rôle de régulation des populations microbiennes (Klieve et Swain 1993).

\section{2 / Facteurs de variation du microbiote digestif équin et santé animale}

Parmi les facteurs susceptibles de modifier la diversité de l'écosystème microbien du gros intestin (caecum, côlon et fèces) équin, nous distinguerons les facteurs intrinsèques qui dépendent de l'animal, les facteurs extrinsèques environnementaux non contrôlables comme le temps ou la saison et les facteurs extrinsèques qui dépendent des choix de conduite pris par la personne en charge du cheval, comme l'alimentation par exemple.

\section{1 / Facteurs liés à l'hôte}

\section{a) Le type génétique}

Seules deux études se sont intéressées à l'effet de la race sur le microbiote fécal en comparant, via l'utilisation de banques de clones (Yamano et al 2008) et de la PCR compétitive (Koike et al 2000), une race locale (Hokkaido) à une 
race légère $(75 \%$ pur-sang et $25 \%$ chevaux légers). Selon la race considérée, la composition de la communauté bactérienne fécale n'était pas la même. En effet, chez les chevaux de race légère, le phylum des Firmicutes était en proportion plus importante que chez les chevaux de race locale (Yamano et al 2008). Chez les chevaux de la race locale cette communauté était en revanche plus diversifiée avec la présence supplémentaire des phyla suivants : Verrucomicrobia, Spirochaetes et Archaea (Yamano et al 2008). Le phylum des Bacteroidetes était présent dans des proportions équivalentes dans les deux races (Yamano et al 2008). Chez les chevaux de race locale, les proportions de certaines populations bactériennes cellulolytiques fécales ( $R$. albus, $R$. flavefaciens et $F$. succinogenes) et de protozoaires fibrolytiques étaient de taille plus importante que chez les chevaux légers (Koike et al 2000, Kobayashi et al 2006, Yamano et al 2008). L'ensemble de ces résultats suggère que le microbiote intestinal des chevaux de race locale serait plus adapté à l'utilisation de fourrages que celui des chevaux légers. Ces conclusions sont confortées par une évolution des paramètres fermentaires représentatifs de l'activité microbienne. En effet, les concentrations en acides gras volatils diminuent pendant la période hivernale lorsque les chevaux (que ce soit de race locale ou légers) consomment des fourrages de pauvre qualité mais cette diminution est significativement moindre pour les chevaux de race locale (Kobayashi et al 2006).

\section{b) Variabilité entre individus}

Des études récentes, menées sur des chevaux adultes, ont montré, via l'utilisation de différentes techniques d'empreinte moléculaire ("Denaturing Gradient Gel Electrophoresis» (DGGE) et «Temperature Gradient Gel Electrophoresis» (TGGE)) que les communautés bactériennes colique et fécale étaient significativement différentes d'un individu à l'autre (Faubladier et al 2006, Grønvold et al 2010). Ces résultats soulignent l'existence d'une spécificité individuelle du microbiote ce qui est en accord avec les données publiées chez le chien (Simpson et al 2002), l'humain (Zoetendal et al 1998), les ovins ou encore les bovins (Edwards et al 2005, Larue et al 2005, Sadet et al 2007).

\section{c) Variabilité temporelle}

La stabilité de la communauté bactérienne fécale équine a été testée, pour un même régime alimentaire, pendant 35 jours (Sadet-Bourgeteau et al 2011) et 90 jours (Endo et al 2007). Quelle que soit la durée de l'expérimentation, aucun effet du temps n'a été observé sur la structure de la communauté bactérienne fécale (Sadet-Bourgeteau et al 2011), ni sur la diversité et la composition en lactobacilles et bifidobactéries fécales (Endo et al 2007). Il semblerait donc que le microbiote fécal équin soit stable dans le temps pour un même individu soumis à un régime alimentaire fixe.

\section{2 / Les facteurs environnemen- taux}

\section{a) Le régime alimentaire}

Le régime alimentaire est certainement le facteur qui a été le plus étudié quant à son impact sur le microbiote intestinal. L'effet de la proportion en amidon dans la ration a été le plus abordé (Adam 1953, Kern et al 1973, Goodson et al 1988, Moore et Dehority 1993, de Fombelle et al 2001, Julliand et al 2001, Medina et al 2002, Vörös 2008, Jouany et al 2009, Willing et al 2009, Daly et al 2012). D'autres facteurs comme un excès de matières grasses dans la ration (Jansen et al 2007), un apport en protéines (Muhonen et al 2008) ou encore le type de fourrage distribué dans la ration (foin, haylage et ensilage d'herbe) (Muhonen et al 2009) ont été testés.

Dans la plupart des études, l'augmentation de la proportion en amidon dans une ration induit une diminution de la concentration en protozoaires dans le caecum (Adam 1953, Goodson et al 1988), une augmentation de cette même concentration en microorganismes dans le côlon (Adam 1953, Moore et Dehority 1993) et une augmentation de la concentration en bactéries anaérobies totales (Kern et al 1973, Goodson et al 1988, de Fombelle et al 2001, Julliand et al 2001, Medina et al 2002, Respondek et al 2007) dans le caecum comme le côlon. Le régime alimentaire aurait également un impact sur la proportion de certaines populations bactériennes et de protozoaires présents dans le gros intestin. Ainsi Kern et al (1973) ont montré chez des poneys que la présence d'amidon dans la ration augmentait significativement le nombre de Blepharocorys uncinata caecaux. Concernant les bactéries, plusieurs études ont mis en évidence qu'une augmentation de la proportion d'amidon dans une ration induisait une augmentation de la concentration en streptocoques (de Fombelle et al 2001, Julliand et al 2001, Medina et al 2002, Respondek et al 2007, Daly et al 2012) dans le caecum comme le côlon. Il a également été montré que l'ajout de céréales dans la ration alimentaire de chevaux conduisait à une augmentation de la concentration en lactobacilles caecaux, coliques et fécaux (de Fombelle et al 2001, Julliand et al 2001, Medina et al 2002, Respondek et al 2007, Vörös 2008, Jouany et al 2009, Willing et al 2009, Daly et al 2012). L'augmentation de la proportion de concentré dans la ration peut également induire une augmentation de la concentration en bactéries utilisatrices de lactate (Goodson et al 1988, Julliand et al 2001, Medina et al 2002, Respondek et al 2007) et une diminution de la concentration en bactéries cellulolytiques, (Julliand et al 2001, Medina et al 2002, Daly et al 2012) que ce soit dans le caecum ou le côlon. Dans leur étude, Daly et al (2012) ont comparé la communauté bactérienne colique entre trois lots de chevaux : un lot nourri avec un régime riche en fourrage et deux autres nourris avec un régime riche en concentré. Ces deux derniers lots se distinguaient par le développement ou non d'une colique d'obstruction (Daly et al 2012). La communauté bactérienne colique est apparue différente entre les chevaux ayant reçu un régime riche en fourrage et ceux nourris avec un régime riche en concentré. Plus précisément, les chevaux nourris avec une ration riche en fourrage présentaient dans le côlon une proportion significativement plus importante de Fibrobacter spp. et de Ruminococcaceae et une proportion moindre de Lachnospiraceae, de Bacteroidetes et de bactéries appartenant au groupe Bacillus-LactobacillusStreptococcus (Daly et al 2012). La composition de la communauté bactérienne des chevaux ayant été nourris avec un régime riche en concentré était similaire, que les chevaux aient développé ou non une colique d'obstruction (Daly et al 2012).

A notre connaissance, l'impact de régimes alimentaires riches en amidon n'a pas été étudié sur la concentration en champignons dans le gros intestin équin.

Dans les fèces, il a été observé que la structure de la communauté bactérienne était différente selon que le régime était riche en fourrage ou en concentré (environ $50 \%$ de la ration) (Vörös 2008 , Willing et al 2009).

Concernant l'excès de matières grasses dans la ration, aucun effet du régime n'a été mis en évidence sur les concentrations en bactéries totales et cellulolytiques du caecum de poneys après vingt et un jour de régime (Jansen et al 2007). La production de gaz mesurée à partir d'échantillons coliques était significativement plus faible pour un régime à forte teneur que pour un régime à faible teneur en matières grasses. Toutefois, la production de gaz n'était pas modifiée pour les échantillons prélevés dans le caecum et les fèces (Jansen et al 2007). Selon ces auteurs, un excès de matières grasses dans la ration inhiberait l'activité 
microbienne dans le caecum, entraînant une diminution de la digestibilité des fibres. Cependant, ceci n'a pas été confirmé par d'autres travaux menés dans notre équipe (Philippeau et al 2008).

Concernant l'apport en protéines, une étude a montré que l'augmentation d'apport protéique dans une ration d'ensilage enrubanné n'entraînait aucune modification sur les concentrations en bactéries dans le côlon (Muhonen et al 2008).

Les perturbations du microbiote provoquées par certaines pratiques d'alimentation peuvent être limitées par l'ajout de probiotiques dans la ration. L'impact d'une supplémentation en probiotiques bactériens sur le microbiote est très peu connu. En revanche, la supplémentation en levures probiotiques (Saccharomyces cerevisiae) a fait l'objet d'un plus grand nombre de travaux chez le cheval (Medina et al 2002, Jouany et al 2009). Les mécanismes d'action des levures s'expriment différemment en fonction de la nature de la ration que reçoivent les chevaux. Avec une ration riche en fourrages, la proportion de bactéries cellulolytiques et les activités fibrolytiques sont plus importantes dans le côlon de chevaux supplémentés que dans celui de chevaux témoins ce qui est en lien avec une augmentation de la dégradation des parois végétales (Medina et al 2002, Jouany et al 2009).

Lorsque les animaux reçoivent un régime riche en céréales et une supplémentation en levures, la concentration en bactéries productrices de lactate augmente dans le caecum des chevaux. La concentration en bactéries utilisatrices de lactate augmente également en proportion plus importante ce qui aboutit à une limitation de la baisse de $\mathrm{pH}$. Chez des chevaux recevant une supplémentation en levures, la diversité bactérienne fécale mesurée par DGGE est plus importante que celle de chevaux témoins (Faubladier et al 2006).

\section{b) La saison}

Chez des chevaux pâturant des prairies de fléole d'avril à novembre, puis des clairières composées essentiellement d'herbe de bambou de décembre à mars, les concentrations fécales en bactéries totales et en protozoaires étaient significativement plus importantes durant l'été que l'hiver (Kobayashi et al 2006). De façon plus précise, la proportion de certains protozoaires cellulolytiques comme Cochliatoxum periachtum augmenterait durant les mois d'hiver. Ces résultats suggèrent un effet de la saison sur le microbiote du gros intestin équin, cependant cet effet pourrait être confondu avec un effet du régime puisque ce dernier varie entre les deux périodes expérimentales.

\section{c) L'anesthésie générale, les trai- tements antibiotiques et anthel- minthiques}

En utilisant la DGGE comme technique d'empreinte moléculaire, aucun effet significatif d'une anesthésie générale n'a été observé sur la structure de la communauté bactérienne fécale (Grønvold et al 2010). De même, aucun effet significatif d'un traitement à la pénicilline n'a été observé (Grønvold et al 2010). Cependant les auteurs soulignent que la forte variabilité individuelle de la structure du microbiote intestinal pourrait masquer les effets potentiels des traitements testés.

\section{d) Le stress de transport}

La structure de la communauté bactérienne fécale équine (estimée par TGGE) a été modifiée trois jours après un transport d'une durée de deux heures (Faubladier et al 2006). L'effet de ce stress de transport sur la structure de la communauté bactérienne fécale a été confirmé par l'utilisation d'une technique d'empreinte moléculaire «Microbial Community Profilingand Characterisation» (Boensma et al 2006). Le transport intervenant généralement avant la réalisation d'une épreuve sportive, la modification du microbiote intestinal occasionnée par ce type de stress est à prendre en compte dans l'optimisation des performances sportives de l'animal.

\section{e) L'exercice physique}

Dougal et al (2005) n'ont observé aucun effet d'un exercice immédiat de $8,9 \mathrm{~km}$ (galop pendant 1,3 km, trot pendant $2,5 \mathrm{~km}$ et marche pendant $5,1 \mathrm{~km}$ ) sur la concentration fécale en bactéries totales et cellulolytiques, ainsi qu'en protozoaires. En 2010, notre équipe a mis en évidence des modifications de l'écosystème microbien fécal chez des chevaux soumis à une période d'entraînement de longue durée (Goachet et al 2010). Plus précisément, la concentration fécale en lactobacilles augmentait entre un état de repos et une course d'endurance de 60 ou $90 \mathrm{~km}$ (de $10^{5}$ à $10^{6} \mathrm{UFC} / \mathrm{g}$ de contenu). En revanche, ce changement de concentration bactérienne n'a pas été observé chez des chevaux passant d'un état de repos à une course de $120 \mathrm{~km}$. Il semblerait que la réalisation d'un effort plus intense (60 et $90 \mathrm{~km} v s 120 \mathrm{~km}$ ) entraîne une diminution significative de la concentration en bactéries anaérobies totales (de 5,01 × $10^{7}$ à $1,26 \times 10^{7} \mathrm{UFC} / \mathrm{g}$ de contenu), utilisatrices de lactate (de $3,98 \times 10^{7}$ à $3,98 \times 10^{6} \mathrm{UFC} / \mathrm{g}$ de conte$\mathrm{nu})$ et des streptocoques (de $2,51 \times 10^{6}$ à
$1,26 \times 10^{6} \mathrm{UFC} / \mathrm{g}$ de contenu) (Goachet et al 2010). D'autres travaux sont nécessaires afin de mieux comprendre les «dysmicrobismes» qui pourraient potentiellement être générés par l'exercice physique ainsi que leurs conséquences sur la santé de l'animal.

\section{3 / «Dysmicrobismes» intesti- naux et pathologies digestives}

Chez des chevaux adultes, la question de la relation entre certaines pathologies digestives et un «dysmicrobisme» intestinal a fait l'objet de plusieurs études (Milinovich et al 2006, Milinovich et al 2007, 2008a et b, Costa et al 2012, Daly et al 2012).

La communauté bactérienne fécale a été comparée, par pyro-séquençage, entre des chevaux sains et des chevaux atteints de colites (Costa et al 2012). Chez les chevaux sains, le phylum des Firmicutes était prédominant $(68 \%)$ et les phyla des Bacteroidetes et des Proteobacteria minoritaires (14 et $10 \%$ respectivement). A l'inverse, chez les chevaux atteints de colites, les Bacteroidetes prédominaient (40\%) et la proportion de Firmicutes diminuait $(30 \%)$ alors que la proportion de Proteobacteria augmentait de $18 \%$ (Costa et al 2012). La proportion de Fusobacteria était également plus élevée que chez les animaux sains (Costa et al 2012). D'après Costa et al (2012) ces données suggèrent que les colites seraient plutôt dues à une «dysbiose» dans le gros intestin équin, qu'à l'implantation et la prolifération de pathogènes au niveau intestinal.

Afin d'établir un éventuel lien entre une modification du microbiote intestinal équin et l'apparition de fourbures (Milinovich et al 2006, 2007, 2008b), un modèle expérimental a été mis au point. Il consiste en l'administration par intubation d'une solution d'oligofructose $(10 \mathrm{~g} / \mathrm{Kg}$ de poids vif $)$ en une dose à des chevaux, déclenchant ainsi la fourbure. L'évolution des communautés bactériennes caecale et fécale, suite à ce traitement, a été suivie pendant plusieurs jours après le jour de distribution de la solution, par séquençage (Milinovich et al 2006), «fluorescence in situ hybridization» (FISH) (Milinovich et al 2007), DGGE et PCR quantitative (Milinovich et al 2008b). L'ensemble des résultats montre que dans le caecum et les fèces, la concentration en streptocoques augmente significativement avant l'apparition des premiers signes histologiques de fourbure (Milinovich et al 2006, Milinovich et al 2007, Milinovich et al 2008b). Suite à cette prolifération massive, la mort de ces bactéries entraînerait la libération de composés cellulaires responsables en 
partie de la genèse de cette pathologie (Milinovich et al 2008).

\section{Conclusion}

La synthèse des données actuelles sur le microbiote intestinal équin souligne la diversité des communautés micro- biennes et leur implication majeure dans la digestion des fibres végétales alimentaires. Différents facteurs sont connus pour modifier la diversité de ce microbiote parmi lesquels le plus étudié est le régime alimentaire. Le lien entre un changement de diversité du microbiote digestif et la santé des équins n'a pas encore été clairement établi. Cependant, la quantification de certains phyla clef comme les Firmicutes, les Bacteroidetes ou encore de groupes bactériens comme les streptocoques, pourrait permettre de prévoir lors de situations à risque, l'apparition de certaines pathologies digestives graves pouvant entraîner une baisse de performance de l'animal voire dans le pire des cas, sa mort.

\section{Références}

Adam K., 1950. The quantity and distribution of the ciliate protozoa in the large intestine of the horse. Parasitology, 41, 301-311.

Adam K., 1953. In vivo observations on the ciliate protozoa inhabiting the large intestine of the horse. J. Gen. Microbiol., 9, 876-884.

Al Jassim R.A.M., Scott P.T., Trebbin A.L., Trott D., Pollitt C.C., 2005. The genetic diversity of lactic acid producing bacteria in the equine gastrointestinal tract. FEMS Microbiol., Lett., 248, 75-81.

Alexander F., Davies M., Muir A., 1970. Bacteriophage-like particles in the large intestine of the horse. Res. Vet. Sci., 11, 592-593.

Baruc C.J., Dawson K.A., Baker J.P., 1983. The characterization and nitrogen metabolism of equine caecal bacteria. In: $8^{\text {th }}$ Equine Nutr. Physiol. Symp., University of Kentucky, USA, 151-156.

Batista A., Chaves U., Cte de Vasconcelos, Fishman O., da Sylva J.O., 1961. Flora micoteca intestinal de equinos e asininos no recife. Inst. Micol. Univ. Recife, 326, 116.

Berg E.L., Fu C.J., Porter J.H., Kerley M.S., 2005. Fructooligosaccharide supplementation in the yearling horse: Effects on fecal $\mathrm{pH}$, microbial content, and volatile fatty acid concentrations. J. Anim. Sci., 83, 1549-1553.

Boensma N., Weyenberg S.v., Panneman H., Mulder L., Timmerman H.M., Hesta M., Buyse J., Janssens G.P.J., Doorn D.A.V., 2006. The effect of transportation and probiotic administration on the microflora of horses using microbial community profiling and characterisation; a pilot study. In: Horse health nutrition: Third Europ. Equine Health \& Nutr. Congr., Faculty of Veterinary Medicine, Ghent University, Merelbeke, Belgium, 83-89.

Bonhomme-Florentin A., 1985. Attachement des Ciliés du caecum de cheval aux fragments végétaux - Dégradation des chloroplastes Attachement des bactéries aux Ciliés du caecum. Reprod. Nutr. Dev., 25, 127-139.

Cann A., Fandrich S., Heaphy S., 2004. Analysis of the virus population present in equine faeces indicates the presence of hundreds of uncharacterized virus genomes. Virus Genes, 30, 151-156.

Choukevitch J., 1911. Etude de la flore bactérienne du gros intestin de cheval. Ann. Inst. Pasteur, 25, 247-276 / 345-367.

Costa M.C., Arroyo L.G., Allen-Vercoe E., Stämpfli H.R., Kim P.T., Sturgeon A., Weese J.S., 2012. Comparison of the fecal microbiota of healthy horses and horses with colitis by high throughput sequencing of the V3-V5 Region of the 16S rRNA gene. PLoS ONE, 7, e41484.
Da Veiga L., Chaucheyras-Durand F., Julliand V., 2005. Comparative study of colon and faeces microbial communities and activities in horses fed a high starch diet. In: $3^{\text {rd }}$ Eur. Conf. Horse Nutr. Pferdeheilkunde. Hannover, Germany, 45-46.

Daly K., Shirazi-Beechey S.P., 2003. Design and evaluation of group-specific oligonucleotide probes for quantitative analysis of intestinal ecosystems: their application to assessment of equine colonic microflora. FEMS Microbiol. Ecol., 44, 243-252.

Daly K., Stewart C.S., Flint H.J., ShiraziBeechey S.P., 2001. Bacterial diversity within the equine large intestine as revealed by molecular analysis of cloned 16S rRNA genes. FEMS Microbiol. Ecol., 38, 141-151.

Daly K., Proudman C.J., Duncan S.H., Flint H.J., Dyer J., Shirazi-Beechey S.P., 2012 Alterations in microbiota and fermentation products in equine large intestine in response to dietary variation and intestinal disease. Br. J. Nutr., 107, 989-995.

de Fombelle A., Julliand V., Drogoul C., Jacotot E., 2001. Feeding and microbial disorders in horses: 1-effects of an abrupt incorporation of two levels of barley in a hay diet on microbial profile and activities. J. Equine Vet. Sci., 21, 439-445.

de Fombelle A., Varloud M., Goachet A.G., Jacotot E., Philippeau C., Drogoul C., Julliand V., 2003. Characterisation of the microbial and biochemical profile of the different segments of the digestive tract in horses fed two distinct diets. Anim. Sci., 77, 293-304.

Dougal K., Rand A.S., Walsh C.P., Newbold C.J., 2005. The effect of exercise on microbial activity in the hindgut of horses. In: Br. Soc. Anim. Sci. Annual Conf., York, UK, 47.

Dougal K., Harris P.A., Edwards A., Pachebat J.A., Blackmore T.M., Worgan H.J., Newbold C.J., 2012. A comparison of the microbiome and the metabolome of different regions of the equine hindgut. FEMS Microbiol. Ecol., 1-11.

Edwards J.E., McEwan N.R., Travis A.J., John Wallace R.J., 2004. 16S rDNA librarybased analysis of ruminal bacterial diversity. Antonie van Leeuwenhoek, 86, 263-281.

Edwards J.E., McEwan N.R., McKain N., Walker N., Wallace R.J., 2005. Influence of flavomycin on ruminal fermentation and microbial populations in sheep. Microbiol., 151, 717-725.

Endo A., Okada S., Morita H., 2007. Molecular profiling of Lactobacillus, Streptococcus, and Bifidobacterium species in feces of active racehorses. J. Gen. Appl. Microbiolo., $53,191-200$
Endo A., Roos S., Satoh E., Morita H., Okada S., 2008. Lactobacillus equigenerosi $\mathrm{sp}$. nov., a coccoid species isolated from faeces of thoroughbred racehorses. Int. J. Syst. Evol. Microbiol., 58, 914-918.

Endo A., Futagawa-Endo Y., Dicks L., 2009. Lactobacillus and Bifidobacterium diversity in horse feces, revealed by PCR-DGGE. Curr. Microbiol., 59, 651-655.

Faubladier C., Julliand V., Veiga L., Chaucheyras-Durand F., 2006. Comparison of colon and faeces microbial diversities in horses using molecular techniques. In: $6^{\text {th }}$ joint INRARRI gastrointestinal Tract Microbiol. Symp., Aberdeen, Scotland.

Gaillard-Martinie B., Breton A., Dusser M., Guillot J., 1992. Contribution to the morphological, cytological and ultrastructural characterization of Piromyces mae, a strictly anaerobic rumen fungus. Curr. Microbiol., 24, 159-164.

Gaillard-Martinie B., Breton A., Dusser M., Julliand V., 1995. Piromyces citronii sp. nov., a strictly anaerobic fungus from the equine caecum: a morphological, metabolic, and ultrastructural study. FEMS Microbiol. Lett., 130, 321-326.

Garrett L.A., Brown R., Poxton I.R., 2002. A comparative study of the intestinal microbiota of healthy horses and those suffering from equine grass sickness. Vet. Microbiol., 87, 81-88.

Goachet A.G., Varloud M., Philippeau C., Julliand V., 2010. Long-term effects of endurance training on total tract apparent digestibility, total mean retention time and faecal microbial ecosystem in competing Arabian horses. Equine Vet. J., 42, 387-392.

Göçmen B., Gürelli G., Dehority B.A., 2012. Fecal ciliate composition of Cypriot domestic horses (Equus caballus Linnaeus, 1758). Turkish J. Zool., 36, 163-170.

Gold J.J., Brent Heath I., Bauchop T., 1988. Ultrastructural description of a new chytrid genus of caecum anaerobe, Caecomyces equi gen. nov., sp. nov., assigned to the Neocallimasticaceae. In: $7^{\text {th }}$ Biennial Meet. Int. Soc. Evol. Protistol. Biosyst., 403-415.

Golomidova A., Kulikov E., Isaeva A., Manykin A., Letarov A., 2007. The diversity of coliphages and coliforms in horse feces reveals a complex pattern of ecological interactions. Appl. Environ. Microbiol., 73, 5975-5981.

Goodson J., Tyznik W.J., Cline J.H., Dehority B.A., 1988. Effects of an abrupt diet change from hay to concentrate on microbial numbers and physical environment in the cecum of the pony. Appl. Environ. Microbiol., 54, 19461950. 
Grønvold A.M.R., L'Abée-Lund T.M., Strand E., Sørum H., Yannarell A.C., Mackie R.I., 2010. Fecal microbiota of horses in the clinical setting: Potential effects of penicillin and general anesthesia. Vet. Microbiol., 145, 366-372.

Gruby D., Delafond O., 1843. Recherches sur des animalcules se développant en grand nombre dans l'estomac et dans les intestins, pendant la digestion des animaux herbivores et carnivores. Compt. Rend. Acad. Sci., 17, 1304 1308.

Gürelli G., Göçmen B., 2009. Intestinal ciliate composition found in the feces of the Cypriot wild donkey, Equus asinus Linnaeus, 1758. Europ. J. Protistol., In Press, Corrected Proof.

Gürelli G., Göçmen B., 2011. Intestinal ciliate composition found in the feces of the Turk rahvan horse Equus caballus, Linnaeus 1758 . Europ. J. Protistol., 47, 245-255.

Gürelli G., Göçmen B., 2012. Intestinal ciliate composition found in the feces of racing horses from Izmir, Turkey. Europ. J. Protistol., 48, 215-226.

Hastie P.M., Mitchell K., Murray J.M.D., 2008. Semi-quantitative analysis of Ruminococcus flavefaciens, Fibrobacter succinogenes and Streptococcus bovis in the equine large intestine using real-time polymerase chain reaction. Br. J. Nutr., 100, 561-568.

Hintz H.F., Argenzio R.A., Schryver H.F., 1971. Digestion coefficients, blood glucose levels and molar percentage of volatile acids in intestinal fluid of ponies fed varying foragegrain ratios. J. Anim. Sci., 33, 992-995.

Hungate R.E., 1950. The anaerobic mesophilic cellulolytic bacteria. Bacteriol. Rev., 14, 1-46.

Ike K., Nuruki R., Mai S., Ishii T., 1983. Compositon of intestinal ciliates and bacteria excreted in feces of the race-horse. Jpn. J. Vet. Sci., 40, 157-163.

Ike K., Mai S., Ishii T., 1985. Establishment of intestinal ciliates in new-born horses. Jpn. J. Vet. Sci., 47, 39-43.

Imai S., Inami K., Morita T., Ike K., Ito A., 1999. Intestinal ciliate composition found in the feces of japanese native kiso horse. Bull. Nippon Vet. Anim. Sci. Univ., 48, 33-38.

Jansen W.L., Cone J.W., Geelen S.N.J., Sloet van Oldruitenborgh-Oosterbaan M.M., Van Gelder A.H., Oude Elferink S.J.W.H., Beynen A.C., 2007. High fat intake by ponies reduces both apparent digestibility of dietary cellulose and cellulose fermentation by faeces and isolated caecal and colonic contents. Anim. Feed Sci. Technol., 133, 298-308.

Jouany J.P., Medina B., Bertin G., Julliand V., 2009. Effect of live yeast culture supplementation on hindgut microbial communities and their polysaccharidase and glycoside hydrolase activities in horses fed a high-fiber or high-starch diet. J. Anim. Sci., 87, 28442852.

Julliand V., 2005. Impact of nutrition on the gastro-intestinal tract in horses. In: $1^{\text {st }}$ Equine Nutr. Conf., Wageningen Acad. Publ., Hannover, Germany, 85-103.

Julliand V., Riondet C., De Vaux A., Alcarz G., Fonty G., 1998. Comparison of metabolic activities between Pyromyces citronii, an equine fungal species, and Pyromyces communis, a ruminal species. Anim. Feed Sci. Technol., 70, 161-168.
Julliand V., de Vaux A., Millet L., Fonty G. 1999. Identification of ruminococcus flavefaciens as the predominant cellulolytic bacteria species of the equine cecum. Appl. Environ. Microbiol., 65, 3738-3741.

Julliand V., de Fombelle A., Drogoul C., Jacotot E., 2001. Feeding and microbial disorders in horses: Part 3-Effects of three hay: grain ratios on microbial profile and activities. J. Equine Vet. Sci., 21, 543-546.

Kern D.L., Slyter L.L., Weaver J.M., Leffel E.C., Samuelsons G., 1973. Pony cecum vs steer rumen: The effect of oats and hay on the microbial ecosystem. J. Anim. Sci., 37, 463-469.

Kern D.L., Slyter L.L., Leffel E.C., Weaver J.M., Oltjen R.R., 1974. Ponies vs steers: microbial and chemical characteristics of intestinal ingesta. J. Anim. Sci., 38, 559-564.

Klieve A.V., Swain R.A., 1993. Estimation of ruminal bacteriophage numbers by pulsedfield gel electrophoresis and laser densitometry. Appl. Environ. Microbiol., 59, 2299-2303.

Kobayashi Y., Koike S., Miyaji M., Hata H., Tanaka K., 2006. Hindgut microbes, fermentation and their seasonal variations in Hokkaido native horses compared to light horses. Ecol. Res., 21, 285-291.

Koike S., Shingu Y., Inaba H., Kawai M., Kobayashi Y., Hata H., Tanaka K., Okubo M., 2000. Fecal bacteria in hokkaido native horses as characterized by microscopic enumeration and competitive polymerase chain reaction assays. J. Equine Sci., 11, 45-50.

Kulikov E., Isaeva A., Rotkina A., Manykin A., Letarov A., 2007. Diversity and dynamics of bacteriophages in horse feces. Microbiol., $76,236-242$.

Larue R., Yu Z., Parisi V.A., Egan A.R., Morrison M., 2005. Novel microbial diversity adherent to plant biomass in the herbivore gastrointestinal tract, as revealed by ribosomal intergenic spacer analysis and rrs gene sequencing. Environ. Microbiol., 7, 530-543.

Letarov A., Kulikov E., 2009. The bacteriophages in human- and animal body-associated microbial communities. J. Appl. Microbiol., 107, 1-13

Li J., Heath I.B., 1993. Chytridiomycetou gut fungi, oft overlooked contributors to herbivore digestion. Can. J. Microbiol., 39, 1003-1013.

Li J., Heath I.B., Bauchop T., 1989. Piromyces mae and Piromyces dumbonica, two new species of uniflagellate anaerobic chytridiomycete fungi from the hindgut of the horse and elephant. Can. J. Bot., 68, 1021-1033.

Liggenstoffer A.S., Youssef N.H., Couger M.B., Elshahed M.S., 2010. Phylogenetic diversity and community structure of anaerobic gut fungi (phylum Neocallimastigomycota) in ruminant and non-ruminant herbivores. ISME J., 4, 1225-1235.

Lin C., Stahl D., 1995. Taxon-specific probes for the cellulolytic genus Fibrobacter reveal abundant and novel equine-associated populations. Appl. Environ. Microbiol., 61, 1348-1351.

Lin C., Miller T.L., 1998. Phylogenetic analysis of Methanobrevibacter isolated from feces of humans and other animals. Arch. Microbiology, 169, 397-403.

Loreau M., Behera N., 1999. Phenotypic diversity and stability of ecosystem processes Theor. Popul. Biol., 56, 29-47.
Mackie R.I., Wilkins C.A., 1988. Enumeration of anaerobic bacterial microflora of the equine gastrointestinal tract. Appl. Environ. Microbiol., 54, 2155-2160.

Maczulak A.E., Dawson K.A., Baker J.P., 1985. Nitrogen utilization in bacterial isolates from the equine cecum. Appl. Environ. Microbiol., 50, 1439-1443.

McCreery S., Fulghum R.S., Baker J.P., 1971. Microflora in the equine cecum. J. Anim. Sci., 33, 234.

Medina B., Girard I.D., Jacotot E., Julliand V., 2002. Effect of a preparation of Saccharomyces cerevisiae on microbial profiles and fermentation patterns in the large intestine of horses fed a high fiber or a high starch diet. J. Anim. Sci., 80, 2600-2609.

Milinovich G.J., Trott D.J., Burrell P.C., Eps A.W.v., Thoefner M.B., Blackall L.L., Jassim R.A.M.A., Morton J.M., Pollitt C.C., 2006. Changes in equine hindgut bacterial populations during oligofructose-induced laminitis. Environ. Microbiol., 8, 885-898.

Milinovich G.J., Trott D.J., Burrell P.C., Croser E.L., Jassim R.A.M.A., Morton J.M., Eps A.W.v., Pollitt C.C., 2007. Fluorescence in situ hybridization analysis of hindgut bacteria associated with the development of equine laminitis. Environ. Microbiol., 9, 2090-2100.

Milinovich G.J., Burrell P.C., Pollitt C.C., Bouvet A., Trott D.J., 2008a. Streptococcus henryi sp. nov. and Streptococcus caballi sp. nov., isolated from the hindgut of horses with oligofructose-induced laminitis. Int. J. Syst. Evol. Microbiol., 58, 262-266.

Milinovich G.J., Burrell P.C., Pollitt C.C., Klieve A.V., Blackall L.L., Ouwerkerk D., Woodland E., Trott D.J., 2008b. Microbial ecology of the equine hindgut during oligofructose-induced laminitis. Int. J. Syst. Evol. Microbiol., 2, 1089-1100.

Miller T.L., Wolin M.J., 1986. Methanogens in human and animal intestinal Tracts. Syst. Appl. Microbiol., 7, 223-229.

Miller T.L., Wolin M.J., Kusel E.A., 1986. Isolation and characterization of methanogens from animal feces. Syst. Appl. Microbiol., 234-238.

Moore B.E., Dehority B.A., 1993. Effects of diet and hindgut defaunation on diet digestibility and microbial concentrations in the cecum and colon of the horse. J. Anim. Sci., 71, 3350-3358.

Morita H., Shiratori C., Murakami M., Takami H., Kato Y., Endo A., Nakajima F. Takagi M., Akita H., Okada S., Masaoka T., 2007. Lactobacillus hayakitensis sp. nov., isolated from intestines of healthy thoroughbreds. Int. J. Syst. Evol. Microbiol., 57, 2836-2839.

Morita H., Nakano A., Shimazu M., Toh H., Nakajima F., Nagayama M., Hisamatsu S., Kato Y., Takagi M., Takami H., Akita H., Matsumoto M., Masaoka T., Murakami M., 2009. Lactobacillus hayakitensis, L. equigenerosi and $L$. equi, predominant lactobacilli in the intestinal flora of healthy thoroughbreds. Anim. Sci., 80, 339-346.

Morotomi M., Yuki N., Kado Y., Kushiro A., Shimazaki T., Watanabe K., Yuyama T., 2002. Lactobacillus equi sp. nov., a predominant intestinal Lactobacillus species of the horse isolated from faeces of healthy horses. Int. J. Syst. Evol. Microbiol., 52, 211-214.

Morvan B., Bonnemoy F., Fonty G., Gouet P., 1996. Quantitative determination of $\mathrm{H} 2$-utilizing acetogenic and sulfate-reducing bacteria and 
methanogenic archaea from digestive tract of different mammals. Curr. Microbiol., 32, 129133.

Muhonen S., Connysson M., Lindberg J.E., Julliand V., Bertilsson J., Jansson A., 2008. Effects of crude protein intake from grass silage-only diets on the equine colon ecosystem after an abrupt feed change. J. Anim. Sci., $86,3465-3472$.

Muhonen S., Julliand V., Lindberg J.E., Bertilsson J., Jansson A., 2009. Effects on the equine colon ecosystem of grass silage and haylage diets after an abrupt change from hay. J. Anim. Sci., 87, 2291-2298.

Nickel R., Schummer A., Seiferle E., 1979. The viscera of domestic animals. SpringerVerlag, New York.

Müller C.E., von Rosen D., Udén P., 2008. Effect of forage conservation method on microbial flora and fermentation pattern in forage and in equine colon and faeces. Livest. Sci., 119, 116-128.

Orpin C., 1981. Isolation of cellulolytic phycomycete fungi from the caecum of the horse. J. Gen. Microbiol., 123, 287-296.

Ozeki K., Imai S., Katsuno M., 1973. On the distribution of the ciliated protozoa in the large intestine of horse. Tohoku J. Agric. Res., 24, 86-101.

Pedrós-Alió C., 2006. Marine microbial diversity: can it be determined? Trends in Microbiol., 14, 257-263.

Peltonen T., Kossila V., Syrjälä L., Immonen I., 1978. Feeding value of grass molasses pellets and their influence on the faecal microbiota of horses. Ann. Agric. Fenn., 17, 109-114.

Philippeau C., Faubladier C., Goachet A.G., Julliand V., 2009. Is there an impact of feeding concentrate before or after forage on colonic $\mathrm{pH}$ and redox potential in horses? In: Applied equine nutrition and training. Equine Nutr. Training Conf. (ENUTRACO). Wageningen Acad. Publ., Madrid, Spain, 203-208.

Respondek F., Goachet A.G., Rudeaux F., Julliand V., 2007. Effects of short-chain fructooligosaccharides on the microbial and biochemical profile of different segments of the gastro-intestinal tract in horses. Pferdeheilkunde, 23, 146-150.

Respondek F., Goachet A.G., Julliand V., 2008. Effects of dietary short-chain fructo- oligosaccharides on the intestinal microflora of horses subjected to a sudden change in diet. J. Anim. Sci., 86, 316-323.

Sadet S., Martin C., Meunier B., Morgavi D.P., 2007. PCR-DGGE analysis reveals a distinct diversity in the bacterial population attached to the rumen epithelium. Animal, 1, 939-944.

Sadet-Bourgeteau S., Philippeau C., Goachet A.G., Faubladier C., Villot C., Julliand V., 2011. Temporal stability of bacterial community structure from equine feces. In: Conf. GastroIntestinal Function, Chicago, USA.

Sekirov I., Russell S.L., Antunes L.C.M., Finlay B.B., 2010. Gut microbiota in health and disease. Physiol. Rev., 90, 859-904.

Shepherd M.L., Swecker W.S., Ponder M.A. 2011. Characterization of the fecal bacterial population in an obese and non-obese horse fed variable carbohydrate hay by use of pyrosequencing: a pilot study. In: $11^{\text {th }}$ Ann. AAVN Clinical Nutr. Res. Symp., Blackwell Publ. Ltd., Denver, Colorado, 808-816.

Shepherd M.L., Swecker W.S., Jensen R.V., Ponder M.A., 2012. Characterization of the fecal bacteria communities of forage-fed horses by pyrosequencing of $16 \mathrm{~S}$ rRNA V4 gene amplicons. FEMS Microbiol. Lett., 326, 62-68.

Simpson J.M., Martineau B., Jones W.E., Ballam J.M., Mackie R.I., 2002. Characterization of Fecal Bacterial Populations in Canines: Effects of Age, Breed and Dietary Fiber. Microbial Ecology, 44, 186-197.

Tajima K., Arai S., Ogata K., Nagamine T., Matsui H., Nakamura M., Aminov R.I., Benno Y., 2000. Rumen bacterial community transition during adaptation to high-grain diet. Anaerobe, 6, 273-284.

Teunissen M.J., Op den Camp H.J.M., 1993. Anaerobic fungi and their cellulolytic and xylanolytic enzymes. Antonie van Leeuwenhoek, 63, 63-76.

Tisserand J.L., Masson C., 1976. Effets de différents régimes sur l'activité biochimique dans le gros intestin du poney. In: $27^{\text {ème }}$ Réunion annuelle de la F.E.Z. Féd. Europ. Zootech., Zurich, SW, 380-390.

Vavra J., Joyon L., 1966. Etude sur la morphologie, le cycle évolutif et la composition systématique de Callimastix cyclopis. Protistol., 2, 5-16.
Vörös A., 2008. Diet related changes in the gastrointestinal microbiota of horses. Swedish University of Agricultural Sciences, Uppsala, Sweden, 36.

Whitford M.F., Forster R.J., Beard C.E., Gong J., Teather R.M., 1998. Phylogenetic analysis of rumen bacteria by comparative sequence analysis of cloned 16S rRNA Genes. Anaerobe, 4, 153-163.

Willing B., Vörös A., Roos S., Jones C., Jansson A., Lindberg J.E., 2009. Changes in faecal bacteria associated with concentrate and forage-only diets fed to horses in training. Equine Vet. J., 41, 908-914.

Wolter R., Gouy D., Durix A., Letourneau J.C., Landreau J., 1978. Digestibilité et activité biochimique intracaecale chez le poney recevant un même aliment complet présenté sous forme granulée, expansée ou semi-expansée. Ann. Zootech., 27, 47-60.

Yamano H., Koike S., Kobayashi Y., Hata H., 2008. Phylogenetic analysis of hindgut microbiota in Hokkaido native horses compared to light horses. Anim. Sci., 79, 234-242.

Yu Z., Yu M., Morrison M., 2006. Improved serial analysis of $\mathrm{V} 1$ ribosomal sequence tags (SARST-V1) provides a rapid, comprehensive, sequence-based characterization of bacterial diversity and community composition. Environ. Microbiol., 8, 603-611.

Yuyama T., Takai S., Tsubaki S., Kado Y., Morotomi M., 2004. Evaluation of a hostspecific lactobacillus probiotic in training-horses and neonatal foals. J. Intest. Microbiol., 18, 101-106.

Zoetendal E.G., Akkermans A.D.L., De Vos W.M., 1998. Temperature gradient gel electrophoresis analysis of $16 \mathrm{~S}$ rRNA from human fecal samples reveals stable and host-specific communities of active bacteria. Appl. Environ. Microbiol., 64, 3854-3859.

Zoetendal E.G., Collier C.T., Koike S., Mackie R.I., Gaskins R.H., 2004. Molecular ecological analysis of the gastrointestinal microbiota: A Review. J. Nutr., 134, 465-472.

\section{Résumé}

Le gros intestin (caecum et côlon) des équins héberge un microbiote abondant et divers dont une fonction essentielle est la dégradation et la fermentation des parois végétales ingérées en produits directement utilisables par l'hôte. Ce microbiote est composé de cinq grandes communautés microbiennes (protozoaires, bactéries, champignons, Archaea et virus) parmi lesquelles les bactéries ont été les plus étudiées. Ces communautés sont spécifiques de l'espèce équine. La diversité des protozoaires comme celle des champignons et des virus a été décrite du point de vue taxonomique mais leur implication dans les processus de digestion est mal connue. La diversité des Archaea a été peu étudiée, pourtant leur étude permettrait de mieux évaluer la contribution de l'élevage équin à la production de gaz à effet de serre. La communauté bactérienne est diverse, appartenant majoritairement aux phyla des Firmicutes et des Bacteroides, et comprend des bactéries dont les différentes fonctions (cellulolytiques, amylolytiques, glycolytiques, utilisatrices de lactate et protéolytiques) sont impliquées dans la digestion des aliments ingérés, en particulier des parois végétales. Cette communauté bactérienne est différente entre le contenu caecal et colique d'une part, et les fèces d'autre part. Des facteurs propres à l'hôte (type génétique, variabilité individuelle) et/ou environnementaux (régime alimentaire, saison, exercice physique) sont susceptibles de modifier la diversité des communautés microbiennes du gros intestin équin. Ceci peut provoquer des changements importants conduisant à des déséquilibres et parfois à l'apparition de pathologies (colites, fourbures). 


\begin{abstract}
The diversity of the microbial ecosystem in the equine digestive tract

The equine large intestine (cecum and colon) hosts numerous and various microbiota, which play an essential role in degrading and fermenting cell-walls into products directly used by the host. This microbiota is made of five major microbial communities (protozoa, bacteria, fungi, Archaea and virus) among which the most investigated are bacteria. These communities are equine specific. Protozoal diversities like fungal and viral ones have been described in terms of taxonomy but there is little knowledge about their implication in the digestive processes. Few studies have been conducted on the diversity of Archeae despite the potential contribution of equine livestock to greenhouse gas production. The bacterial community is diverse, belonging predominantly to the Firmicutes and Bacteroides Phyla, and including bacteria with a wide range of functions (cellulolytics, amylolytics, glycolytics, lactate-utilizers and proteolytics) that are implicated in the ingested feed digestion, mainly plant fiber. This bacterial community differs between the cecal and colonic content and the fecal content. Factors specific to the host (genotype, individual variability) and/or environmental (diet, season, exercise) may alter the microbial communities' diversity of the equine large intestine. This can induce large changes leading to imbalances and sometimes to pathologies (colics, laminitis).
\end{abstract}

SADET-BOURGETEAU S., JULLIAND V., 2012. La diversité de l'écosystème microbien du tractus digestif équin. INRA Prod. Anim., 25, 5, 407-418. 